\title{
Cyclic viscoplastic deformation modeling of a nickel-based single crystal superalloy with [001] orientation
}

\author{
Rongqiao Wang ${ }^{1,2,3}$, Bin Zhang ${ }^{1}$, Dianyin $\mathrm{Hu}^{1,2,3,{ }^{*}}$, Kanghe Jiang ${ }^{4}$, Jianxing Mao ${ }^{1}$, Fulei Jing $^{5}$ \\ ${ }^{1}$ School of Energy and Power Engineering, Beihang University, Beijing 100191, China \\ ${ }^{2}$ Beijing Key Laboratory of Aero-Engine Structure and Strength, Beijing 100191, China \\ ${ }^{3}$ Collaborative Innovation Center of Advanced Aero-Engine, Beijing 100191, China \\ ${ }^{4}$ AECC Hunan Aviation Powerplant Research Institute, Zhuzhou 412000, China \\ ${ }^{5}$ Aero Engine Corporation of China, Beijing 101304, China
}

\begin{abstract}
Accurate simulations of cyclic viscoplastic deformation behaviors of single crystal superalloys which are widely used for the manufacture of gas turbine blades are important for the effective design and safety assessment in practice. In this context, based on the in-phase thermomechanical fatigue (IP TMF) and out-of-phase thermomechanical fatigue (OP TMF) experiments of the nickel-based single crystal superalloy with [001] orientation, a modified constitutive model has been developed to describe the deformation behavior under thermomechanical loadings. The TMF experiment results indicate that stable hysteresis loops with remarkable ratcheting appear in both IP TMF and OP TMF. And it's worth noticing that the ratcheting growth direction of IP TMF and OP TMF are opposite. By introducing a Schmid stress rate related term to the back stress evolution equation, the slip-based Walker's constitutive model is modified in this study. And the simulation results of the deformation behavior reveal good agreement with the experiments under different IP TMF and OP TMF conditions.
\end{abstract}

\section{Introduction}

Due to excellent performance at elevated temperature, nickel-based single crystal superalloys have been widely used in turbine blades and vanes in gas turbine engines $[1,2]$. Generally, the preferred orientation of the single crystal turbine blade to subject the centrifugal loading is [001] orientation [1,3]. For gas turbine blades, TMF caused by the simultaneously centrifugal loadings and thermal loadings during the repeated engine operations is a major life-limiting factor $[4,5]$. And the first step in the calculation of fatigue life for the structural components, is the determination of stress-strain cycles [6]. Therefore, it is of great significance to investigate the TMF behavior and its accurate simulation method of the nickel-based single crystal superalloy with $<001>$ orientation.

The unified viscoplastic constitutive models are widely applied to describe the viscoplastic deformation behaviors [7]. Previous researchers such as Walker, Chaboche, Bodner and Miller have proposed numerous viscoplastic models [8-11]. Since the nickel-based single crystal superalloys are orthotropic, it is necessary to consider the anisotropy in the viscoplastic constitutive model. A tensor-based mathematic approach is introducing a four order tensor in the constitutive model to characterize the anisotropy of the material [12-14]. Another method is a slip-based method which establishes flow rules and evolution equations of internal variables in the slip system based on the assumption that the inelastic deformation of the material is entirely caused by the slip [15-17]. Compared with the tensorbased method, the slip-based method could reflect the micro-deformation mechanism of the material and describe the phenomenon of slip in the deformation process of the nickel-based single crystal superalloy.

A series of fatigue and creep-fatigue tests clarify that the tensile ratcheting decreases the fatigue life [18]. Therefore, determination of the ratcheting is an important issue in the design of components in automotive, aerospace and aeronautics industries [19]. However, the accurate simulation of ratcheting in unified viscoplastic models is still a challenge [20-23]. In order to improve the accuracy of ratcheting simulation, a variety of modified approaches about kinematic hardening and dynamic recovery have been proposed, and achieved great results at specific conditions. [24-26]. However, there are few reports about the quantitative simulation of the IP TMF and OP TMF ratcheting behaviors which is observed under stress controlled loading with zero mean stress of the nickel-based single crystal superalloy.

In this regard, the objective of this paper is to develop a constitutive model to simulate the cyclic viscoplastic deformation of the nickel-based single crystal superalloy accurately. Firstly, stress-controlled TMF experiments were conducted to investigate the deformation behavior of the nickel-based single crystal superalloy with [001] orientation. Then, a modified slip-

Corresponding author: hdy@buaa.edu.cn 
based viscoplastic constitutive model was established through introducing a Schmid stress rate related term to the back stress evolution equation and the material constants were identified by fitting the experimental data. Finally, deformation behaviors of the nickel-based single crystal superalloy under LCF (low cycle fatigue) and TMF loadings were simulated, and the simulation results showed a good agreement with the experiment results.

\section{Material and deformation behavior}

\subsection{Material}

The material used in present work is a nickel-based single crystal superalloy casted along [001] orientation. The chemical composition and basic mechanical properties at different temperatures of the alloy are given in Table 1 and Table 2, respectively. According to the crystal orientation analysis, the crystal orientation deviations of the material less than $10^{\circ}$ from [001] direction. And the materials have experienced the solution heat treatments at $1290{ }^{\circ} \mathrm{C}$ for $1 \mathrm{~h}$, then at 1300 ${ }^{\circ} \mathrm{C}$ for $2 \mathrm{~h}$, then at $1315^{\circ} \mathrm{C}$ for $4 \mathrm{~h}$ and then air-cooled. Subsequently, a two-stage aging treatment consisting of heat treatment at $1120{ }^{\circ} \mathrm{C}$ for $4 \mathrm{~h}$ and at $870{ }^{\circ} \mathrm{C}$ for $32 \mathrm{~h}$ is performed to achieve the designed $\gamma / \gamma^{\prime}$ microstructure (Fig 1). For nickel-based single crystal superalloy used in this study, the volume fraction of $\gamma^{\prime}$ precipitates dispersed in $\gamma$-matrix is typically about $70 \%$ at room temperature and the size of cuboidal $\gamma^{\prime}$-particles is about $0.5 \mu \mathrm{m}$ measured along the cube edge. In general, the main source of hardening in nickel-based single crystals is provided by the $\gamma^{\prime}$ precipitates.

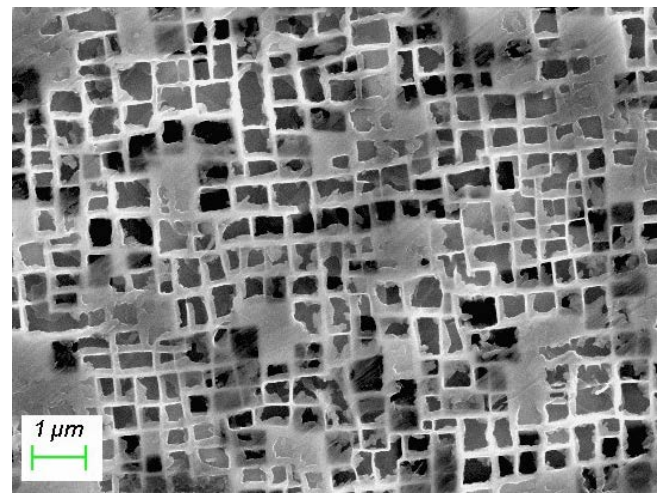

Fig 1. $\gamma / \gamma^{\prime}$ microstructure of the nickel-based single crystal superalloy.

Table 1. Chemical composition of the material (wt. \%).

\begin{tabular}{|c|c|c|c|c|c|c|c|c|}
\hline $\mathrm{Ni}$ & $\mathrm{Al}$ & $\mathrm{Ta}$ & $\mathrm{W}$ & $\mathrm{Co}$ & $\mathrm{Re}$ & $\mathrm{Hf}$ & $\mathrm{Cr}$ & $\mathrm{Mo}$ \\
\hline Balance & $5.2 \sim 6.2$ & $6.0 \sim 8.5$ & $7.0 \sim 9.0$ & $8.5 \sim 9.5$ & $1.6 \sim 2.4$ & $0.05 \sim 0.15$ & $3.8 \sim 4.8$ & $1.5 \sim 2.5$ \\
\hline
\end{tabular}

Table 2. Mechanical properties of the nickel-based single crystal superalloy in $<001>$ direction.

\begin{tabular}{|c|c|c|c|c|c|c|}
\hline Temperature $\left({ }^{\circ} \mathrm{C}\right)$ & 25 & 700 & 760 & 850 & 980 & 1070 \\
\hline Elastic modulus $(\mathrm{GPa})$ & 131.5 & 107.0 & 105.5 & 98.0 & 80.5 & 69.5 \\
\hline Shear modulus $(\mathrm{GPa})$ & 137.0 & 100.2 & 105.0 & 60.6 & 80.4 & 74.2 \\
\hline Poisson ratio & 0.344 & 0.374 & 0.377 & 0.383 & 0.390 & 0.399 \\
\hline
\end{tabular}

\subsection{TMF deformation behavior}

The hollow tubular uniaxial specimens used in the experiments were machined from the cast bars of the nickel-based single crystal superalloy, with axes parallel to [001] orientation. For the specimens, the gage section length was $25 \mathrm{~mm}$, the outside diameter was $12.0 \mathrm{~mm}$ and the inside diameter was $9.0 \mathrm{~mm}$. All of the TMF experiments were conducted under stress control with stress ratio $\mathrm{R}=-1$ and frequency $\mathrm{f}=0.01$.

The deformation behaviors under IP-TMF and OPTMF conditions are shown in Fig 2. As can be seen, stable hysteresis loops with obvious ratcheting behaviors are found in both IP-TMF and OP-TMF, while the ratcheting direction is opposite. In addition, the hysteresis loop of the initial cycle is significantly asymmetric. Specifically, under IP TMF conditions, the tensile deformation is greater than the compressive deformation, which is opposite under OP TMF conditions. One reason is that the temperature at the tensile half-cycle of IP TMF and the compressive halfcycle of OP TMF is higher and the deformation behaviors of the materials at high temperature are greater than the deformation behaviors at low temperature. Of course, the nickel-based single crystal superalloy investigated in this study has the property of tensioncompression asymmetry under isothermal cyclic loading [27], which would also have a certain influence on the deformation behavior. In addition, with the increase of 
stress amplitude, the ratcheting of both IP TMF and OP TMF increases obviously.

Based on the experimental results, it could be seen that the TMF deformation behavior simulation of the nickel-based single crystal superalloy mainly includes the accurate simulation of asymmetry of hysteresis loop and the ratcheting with opposite evolution direction in IP TMF and OP TMF. Therefore, the constitutive model established should accurately reflect these two aspects.
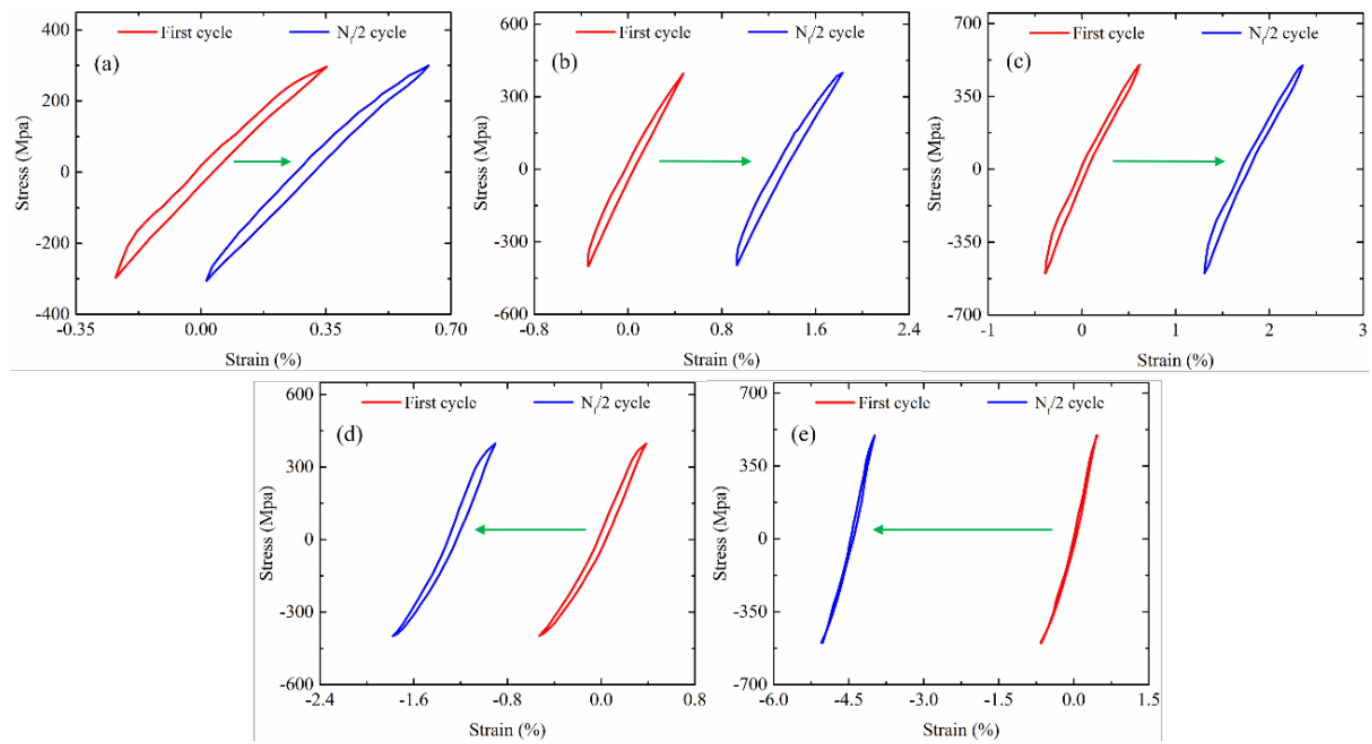

Fig 2. The TMF stress-strain hysteresis loops under $500^{\circ} \mathrm{C}-980^{\circ} \mathrm{C}$ : hysteresis loops of IP TMF with stress amplitude (a) $300 \mathrm{MPa}$, (b) $400 \mathrm{MPa}$, (c) $500 \mathrm{MPa}$; hysteresis loops of OP TMF with stress amplitude (d) $400 \mathrm{MPa}$; (e) $500 \mathrm{MPa}$. The green arrow indicates the direction of ratcheting.

\section{Slip-based viscoplastic constitutive model}

Slip-based Walker's constitutive model has been used to simulate the deformation behavior of the nickel-based single crystal superalloy such as PWA1480 and Hastelloy-X, and the simulation results show that this model could reflect the properties of anisotropy, cyclic hardening/softening and ratcheting accurately [15,28]. Thus we employ the slip-based Walker's constitutive model to describe the viscoplastic behavior in this paper.

In slip-based Walker's constitutive model, the total strain $\boldsymbol{\varepsilon}_{m}$ is composed of elastic strain $\boldsymbol{\varepsilon}_{e}$ and inelastic strain $\varepsilon_{i n}$ as given by

$$
\boldsymbol{\varepsilon}_{m}=\boldsymbol{\varepsilon}_{e}+\boldsymbol{\varepsilon}_{\text {in }}
$$

On the basis of the Hooke's law, the elastic strain $\varepsilon_{e}$ is governed as

$$
\sigma=C: \varepsilon_{e}
$$

where $\sigma$ is the macroscopic stress tensor and $\boldsymbol{C}$ is the stiffness tensor. For nickel-based single crystal superalloy with face centered cubic (FCC) structure, the stiffness tensor $\boldsymbol{C}$ can be given as follows:

$$
\begin{gathered}
\boldsymbol{C}=\left[\begin{array}{cccccc}
c_{11} & c_{12} & c_{12} & 0 & 0 & 0 \\
c_{12} & c_{11} & c_{12} & 0 & 0 & 0 \\
c_{12} & c_{12} & c_{11} & 0 & 0 & 0 \\
0 & 0 & 0 & c_{44} & 0 & 0 \\
0 & 0 & 0 & 0 & c_{44} & 0 \\
0 & 0 & 0 & 0 & 0 & c_{44}
\end{array}\right] \\
c_{11}=\frac{(1-\mu)}{(1-2 \mu)(1+\mu)} E \\
c_{12}=\frac{(1-2 \mu)(1+\mu)}{(1-\mu} E \\
c_{44}=G
\end{gathered}
$$

where $E, G$ and $\mu$ are elastic modulus, shear modulus and Poisson ratio, respectively. The values of them at different temperatures are shown in Table 2 [29].

According to the crystal plasticity theory, the deformation of the crystal is caused by the slip along a specific slip system. For the nickel-based single crystal superalloy, 12 octahedral slip systems $\{111\}<011>$ and 6 cube slip systems $\{100\}<011>$ are generally considered in the crystallographic model. The relationship between the inelastic strain rate $\dot{\boldsymbol{\varepsilon}}_{i n}$ and the slip rate $\dot{\gamma}^{r}$ in the $r$ th slip system could be expressed as follows:

$$
\dot{\boldsymbol{\varepsilon}}_{i n}=\sum_{r=1}^{18} \dot{\gamma}^{r}\left(\boldsymbol{m}^{r} \otimes \boldsymbol{n}^{r}\right)
$$


where $\boldsymbol{m}^{r}$ and $\boldsymbol{n}^{r}$ are the vector of slip direction and normal vector of the slip plane, respectively. Meanwhile, the Schmid stress $\pi^{r}$ in the $r$ th slip system is given by

$$
\pi^{r}=\boldsymbol{\sigma}:\left(\boldsymbol{m}^{r} \otimes \boldsymbol{n}^{r}\right)
$$

K.P. Walker [15] assumed that the shear stress and the inelastic shear strain rate (slip rate) on the slip system followed the similar form of the isotropic Walker's viscoplastic constitutive mode [8], and established a viscoplastic constitutive model based on slip system. The simulation results of PWA1480 and Hastelloy-X show that slip-based Walker's constitutive model could simulate the deformation behavior of nickel-based single crystal superalloy accurately $[15,24,28,30]$. In general, for nickel-based single crystal superalloys, only octahedral slip systems are active when the uniaxial load is applied along [001] orientation. In slip-based Walker's constitutive model, the slip rate in the octahedral slip system is defined:

$$
\dot{\gamma}^{o}=\left|\frac{\pi^{o}-\omega^{o}}{K^{\prime}}\right|^{n-1}\left(\frac{\pi^{0}-\omega^{o}}{K^{o}}\right)
$$

where $\pi^{o}, \omega^{o}$ and $K^{o}$ are the Schmid stress, back stress and drag stress in the octahedral slip system, respectively. In slip-based Walker's constitutive model, $\omega^{\circ}$ and $K^{o}$ describe the kinematic hardening and isotropic hardening respectively. And they are defined as follows:

$$
\begin{gathered}
\dot{\omega}^{o}=\rho_{1}^{\theta} \dot{\gamma}^{o}-\rho_{2}^{o}\left|\dot{\gamma}^{\prime \prime}\right| \omega^{o}-\rho_{3}^{o}\left|\omega^{o}\right|^{p-1} \omega^{o} \\
K^{o}=K_{0}^{o}+\rho_{4}^{o} \pi_{n z}^{o}+\rho_{5}^{o}\left|\Psi^{o}\right|
\end{gathered}
$$

where $\rho_{1}^{o}, \rho_{2}^{o}, \rho_{3}^{o}, \rho_{4}^{o}, \rho_{5}^{o}, n, p$ and $K_{0}^{o}$ are material constants in octahedral slip system. In addition, $\pi_{n z}^{o}$ and $\Psi^{o}$ are non-Schmid stress and Takeuchi-Kuramoto stress, respectively. The calculation methods of them could be seen in reference [24]. Previous research shows that the slip-based Walker's constitutive model has poor accuracy of ratcheting simulation under TMF condition [24]. In order to improve the simulation accuracy, using the similar modification form in reference [24], the back stress evolution equation in this study is modified to

$$
\dot{\omega}^{\prime \prime}=\rho_{1}^{\theta} \dot{\gamma}^{\prime \prime}+\rho_{6}^{\theta} \xi\left(\dot{\pi}^{\prime}\right)^{3}-\rho_{2}^{\theta}\left|\dot{\gamma}^{\theta}\right| \omega^{\theta}-\rho_{3}^{\theta}\left|\omega^{\theta}\right|^{p-1} \omega^{\prime \prime}
$$

where $\dot{\pi}^{o}$ is the rate of Schmid stress, $\rho_{6}^{o}$ is a material constant related to loading conditions and materials in the octahedral slip system, and $\xi$ is a scaling factor which is defined:

$$
\xi=\frac{1}{2}\left|\operatorname{sign}\left(\dot{\gamma}^{\circ}\right)-\frac{\omega^{\circ}}{\rho_{1}^{o} / \rho_{2}^{\prime \prime}}\right|
$$

\section{Simulation of cyclic viscoplastic behavior}

\subsection{Simulations under LCF loadings}

The material constants of Walker's constitutive model listed in Table 1 are identified by fitting the uniaxial standard specimen experimental data which are from reference [29,31,32]. Using Walker's constitutive model with the material constants in Table 1, LCF deformation behaviors at $760^{\circ} \mathrm{C}$ and $980^{\circ} \mathrm{C}$ of the nickel-based single crystal superalloy are simulated. And the simulation results of hysteresis loops, cyclic responses of stress range and cyclic stress-strain curve are shown in Fig. $3 \sim 5$ respectively. The results indicate that Walker's constitutive model could accurately describe the LCF deformation of the nickel-based single crystal superalloy in [001] orientation.

Table 3. Material constants for the constitutive model in the octahedral $\{111\}<001>$ slip systems.

\begin{tabular}{|c|c|c|c|c|c|c|c|c|}
\hline Material constants & $\rho_{1}^{o}$ & $\rho_{2}^{o}$ & $\rho_{3}^{o}$ & $\rho_{4}^{o}$ & $\rho_{5}^{o}$ & $n$ & $p$ & $K_{0}^{o}$ \\
\hline Values at $760^{\circ} \mathrm{C}$ & $\begin{array}{c}1.0345 \\
\times 10^{6}\end{array}$ & $\begin{array}{c}8.4504 \\
\times 10^{3}\end{array}$ & $5.3 \times 10^{-7}$ & 0 & 0.1 & 4.9 & 3.2 & $\begin{array}{c}1.5862 \\
\times 10^{3}\end{array}$ \\
\hline Values at $980^{\circ} \mathrm{C}$ & $\begin{array}{c}1.9150 \\
\times 10^{6}\end{array}$ & $\begin{array}{c}7.6600 \\
\times 10^{3}\end{array}$ & $1.0 \times 10^{-8}$ & 0 & -0.5 & 2.7 & 1.5 & $\begin{array}{c}1.8620 \\
\times 10^{3}\end{array}$ \\
\hline
\end{tabular}



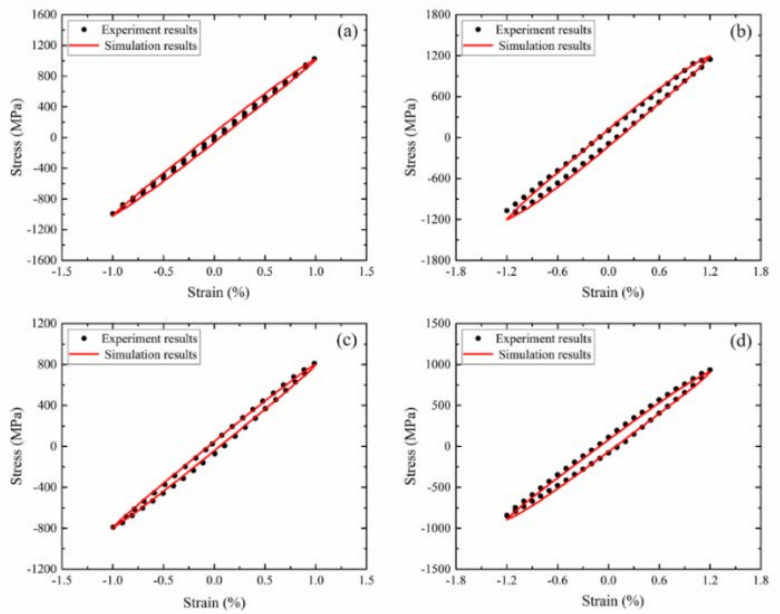

Fig 3. The experimental and simulated LCF stress-strain hysteresis loops under strain rates $5 \times 10^{-3} / \mathrm{s}^{-1}$ : (a) temperature: $760^{\circ} \mathrm{C} / \mathrm{strain}$ range: $\pm 1.0 \%$; (b) temperature: $760^{\circ} \mathrm{C} /$ strain range: $\pm 1.2 \%$; (c) temperature: $980^{\circ} \mathrm{C} /$ strain range: $\pm 1.0 \%$; (d) temperature: $980^{\circ} \mathrm{C} /$ strain range: $\pm 1.2 \%$.

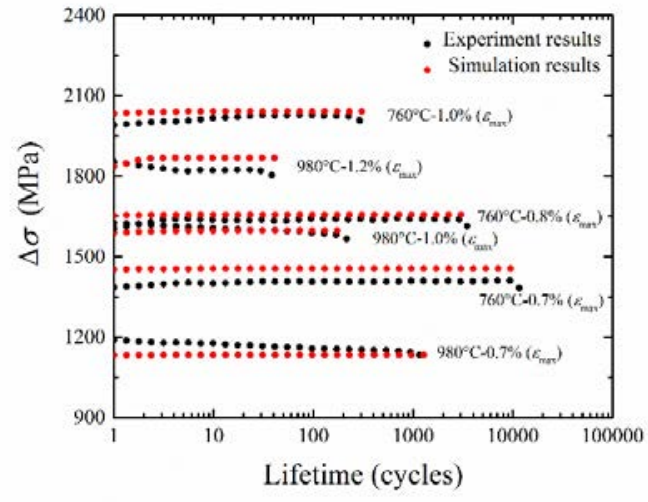

Fig 4. The experimental and simulated LCF cyclic responses of stress range at $760^{\circ} \mathrm{C}$ and $980^{\circ} \mathrm{C}$ with $\mathrm{R}=-1$.

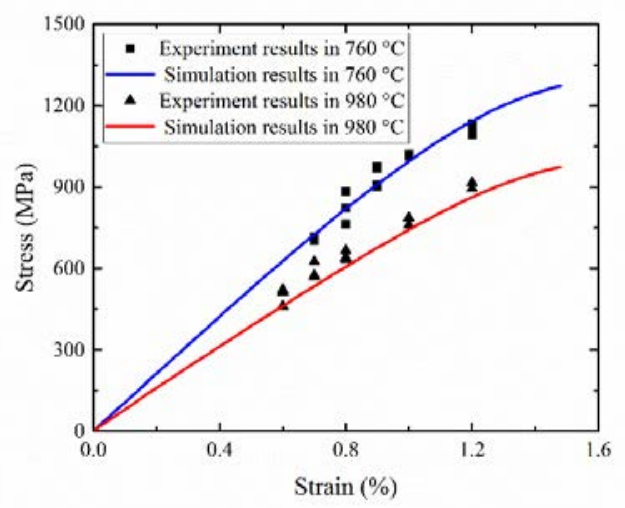

Fig 5. The experimental and simulated LCF cyclic stress-strain curve at $760^{\circ} \mathrm{C}$ and $980^{\circ} \mathrm{C}$ with $\mathrm{R}=-1$.

\subsection{Simulations under TMF loadings}

Based on the TMF experimental results of the nickelbased single crystal superalloy in [001] orientation, it is found that the material constant $\rho_{6}^{o}$ in octahedral $\{111\}$ $<001>$ slip systems could be expressed as follows:

$$
\rho_{6}^{o}=\alpha^{o} \Delta \pi^{o}+\beta^{o}
$$

where $\Delta \pi^{o}$ is the amplitude of Schmid stress. In addition, $\alpha^{o}$ and $\beta^{o}$ are the material constants in octahedral slip systems. For IP TMF and OP TMF experiments at $500^{\circ} \mathrm{C}-980^{\circ} \mathrm{C}$, the values of $\alpha^{\circ}$ and $\beta^{\circ}$ are shown in Table 4. The experimental and simulated TMF deformation behaviors of the nickel-based single crystal superalloy is shown in Fig 6. As can be seen, the simulation results and experiment results under different experimental conditions show a good agreement.

Table 4. Material constants in modified constitutive model.

\begin{tabular}{|c|c|c|}
\hline Material constants & $\alpha^{o}$ & $\beta^{o}$ \\
\hline Values in IP TMF & $3.478 \times 10^{-4}$ & $-7.067 \times 10^{-2}$ \\
\hline Values in OP TMF & $5.344 \times 10^{-4}$ & $-1.062 \times 10^{-1}$ \\
\hline
\end{tabular}



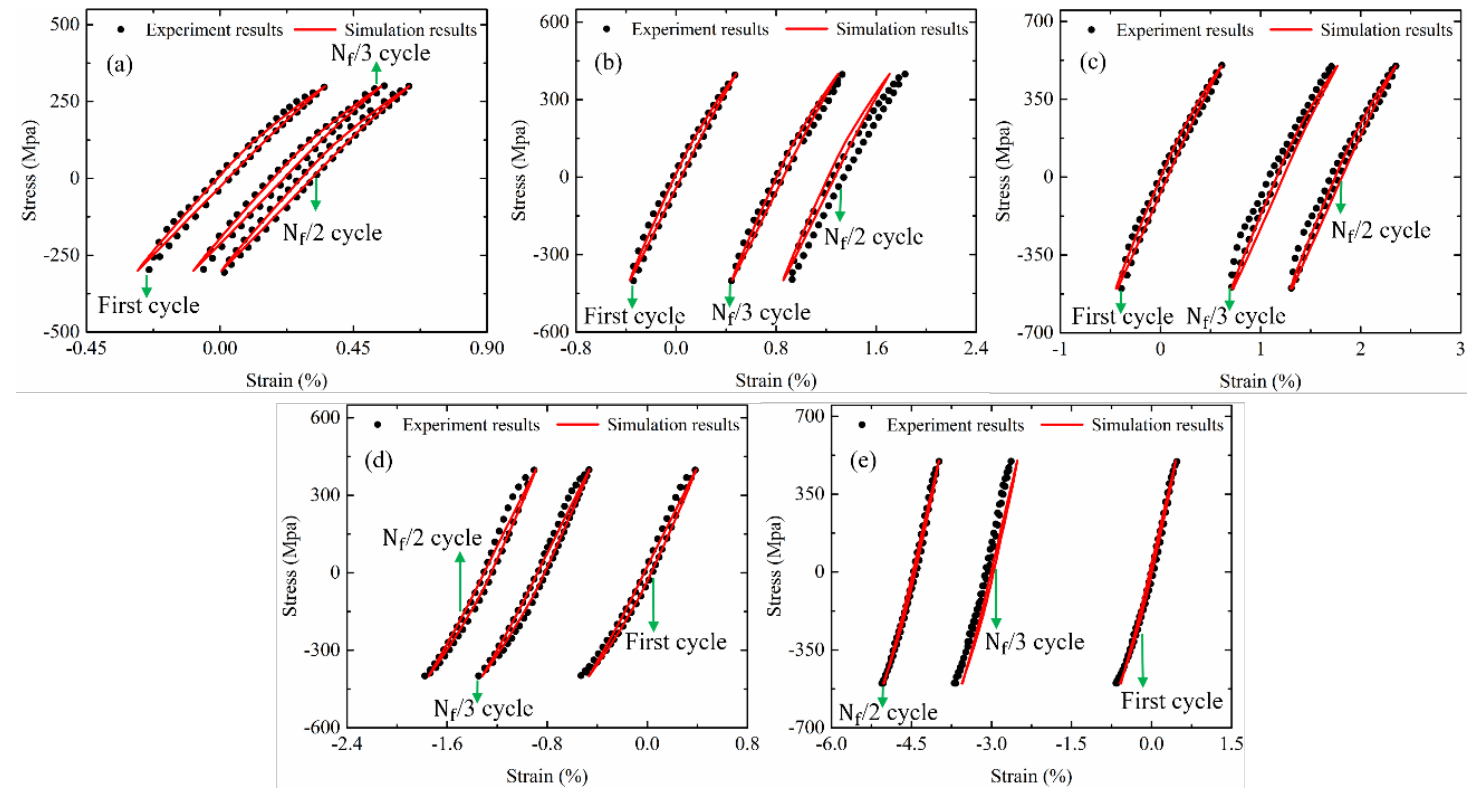

Fig 6. The experimental and simulated TMF stress-strain hysteresis loops under $500^{\circ} \mathrm{C}-980^{\circ} \mathrm{C}$ : hysteresis loops of IP TMF with stress amplitude (a) $300 \mathrm{MPa}$, (b) $400 \mathrm{MPa}$, (c) $500 \mathrm{MPa}$; hysteresis loops of OP TMF with stress amplitude (d) $400 \mathrm{MPa}$ OP; (e) $500 \mathrm{MPa} . N_{f}$ indicates the lifetime of the specimen.

\subsection{Comparison of of classical and modified models}

In order to verify the modification effect, the simulations of the TMF deformation behaviors are conducted through Walker's constitutive model and modified constitutive model respectively. Both the classical and modified constitutive model could simulate the TMF hysteresis loops of the nickel-based single crystal superalloy. Meanwhile, the ratcheting simulation results are in good agreement with the experimental results when the stress amplitude reaches $500 \mathrm{MPa}$. However, for Walker's constitutive model, when the stress amplitude is small (such as $300 \mathrm{MPa}$ and $400 \mathrm{MPa}$ ), the simulated results in both IP TMF and OP TMF show excessive ratcheting, and the overestimation degree is reduced with the increase of the stress amplitude (see Fig. 7). After modification, the simulation capability of the constitutive model is much better in ratcheting simulation for the condition of $300 \mathrm{MPa}$ and $400 \mathrm{MPa}$. It indicated that the modified method in this study has a good effect on improving the ratcheting simulation capability of Walker's constitutive model at lower stress amplitude.

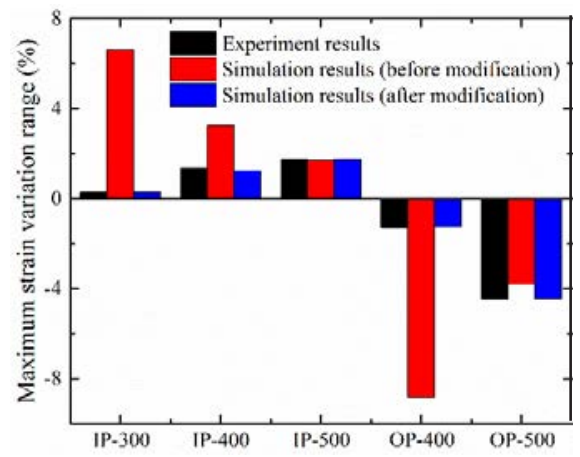

Fig 7. Comparison of experiment and simulation results of the maximum strain variation range after $\mathrm{N}_{\mathrm{f}} / 2$ cycles.

\section{Conclusions}

Based on the TMF experiments conducted in this study, a modified constitutive model has been developed to describe the deformation behaviors of the nickel-based single crystal superalloys under thermomechanical loadings in this study. The detailed conclusions are summarized as follows:

(1) Stress-controlled IP TMF and OP TMF experiments of the nickel-based single crystal superalloy with [001] orientation was conducted. The hysteresis loops are stable in at least half-life period. And the remarkable ratcheting increases along the opposite direction in IP TMF and OP TMF, respectively.

(2) Based on the existing experimental data, the material constants of Walker's constitutive model were identified. And the simulation results of the deformation behaviors under LCF loadings are in good agreement with the experiment data, which verifies the strong simulation capability of the Walker's constitutive model in LCF deformation simulations.

(3) Combined with the deformation characteristics of the nickel-based single crystal superalloy under TMF loading, a Schmid stress rate related term is introduced to the back stress evolution equation of slip-based Walker's constitutive model for changing the evolution rate of the back stress. Through this method, a modified constitutive model has been developed, and the simulation results under different IP TMF and OP TMF loadings show a good agreement with the experiment results.

(4) Compared with the unmodified constitutive model, the modified constitutive model could inhibit the ratcheting under low stress amplitude conditions effectively. On the basis of the existing TMF experimental data, the accuracy of ratcheting simulation 
improves significantly after modifying the constitutive model.

\section{Acknowledgements}

We acknowledge financial support from National Natural Science Foundation of China (NSFC) (Grants No. 51375031 and 51675024).

\section{References}

1. R.C. Reed, The superalloys: fundamentals and applications (Cambridge University Press, Cambridge, 2006)

2. A. Staroselsky, B.N. Cassenti, Int. J. Solids. Struct 48, 13 2060-2075 (2011)

3. Z. Wen, D. Zhang, S. Li, et al, J. Alloy. Compd 692 , 301-312 (2016)

4. R.L. Amaro, S.D. Antolovich, R.W. Neu, A. Staroselsky, Procedia. Eng 2, 1 815-824 (2010)

5. J.J. Moverare, S. Johansson, R.C. Reed, Acta. Mater 57, 7 2266-2276 (2009)

6. O.U. Colak, Mater. Design 29, 8 1575-1581 (2008)

7. A.V.J. Luis, C.M. Stewart, Proceedings of the ASME 2015 International Mechanical Engineering Congress and Exposition, (IMECE2015-50390, 2015)

8. K.P. Walker, Research and development program for nonlinear structural modeling with advanced time-dependent constitutive relationships (NASACR-165533, 1981)

9. J.L. Chaboche, Acad. Polon. Sci, Ser. Sci. Tech 25, 1 33-39 (1977)

10. S.R. Bodner, Y. Partom, J. Appl. Mech 42, 2 385389 (1975)

11. A. Miller, J. Eng. Mater-T. ASME 98, 2 97-105 (1976)

12. A. Baltov, A. Sawcauk, Acta. Mech 1, 2 81-92 (1965)

13. G.A. Swanson, I. Linask, D.M. Nissley, et al, Life prediction and constitutive models for engine hot section anisotropic materials program: annual status report (NASA-CR-174952, 1986)

14. G.A. Swanson, I. Linask, D.M. Nissley, et al, Life prediction and constitutive models for engine hot section anisotropic materials program: second annual status report (NASA-CR-174954, 1987)

15. K.P. Walker, E.H. Jordan, Biaxial constitutive modelling and testing of a single crystal superalloy at elevated temperatures (Mechanical Engineering Publications, London, 145-170, 1989)

16. D. Nouailhas, A.D. Freed, J. Eng. Mater. Technol 114, 1 97-104 (1992)

17. L.T. Dame, D.C. Stouffer, J. Appl. Mech 55, 2 325331 (1988)
18. S. Date, H. Ishikawa, T. Otani, et al, Nucl. Eng. Des 238, 2 336-346 (2008)

19. A. Navarro, J.M. Giráldez, C. Vallellano, Int. J. Fatigue 27, 8 838-846 (2005)

20. D.L. Mcdowell, A.B. Lamar, Advances in Plasticity, (247-251, 1989)

21. J.L. Chaboche, Int. J. Plasticity 7, 7 661-678 (1991)

22. J.L. Chaboche, Advances in Plasticity, (211-214, 1989).

23. E. Krempl, M.B. Ruggles, J. Mech. Phys. Solids 38, 4 587-597 (1990)

24. E.H. Jordan, K.P. Walker, J. Eng. Mater-T. ASME 114, 1 19-26 (1992)

25. J.L. Chaboche, Eur. J. Mech. A-Solid 13, 501-518 (1994)

26. X. Chen, R. Jiao, Int. J. Plasticity 20, 4 871-898 (2004)

27. Y. Li, B. Su, J. Mater. Eng, 5 7-10 (2002)

28. E.H. Jordan, S.X. Shi, K.P. Walker, Int. J. Plasticity 9, 1 119-139 (1993)

29. H. Yu, X. Wu, et al, Materials handbook for aeroengine design (fourth) (Aviation Industry Press, Beijing, 2010)

30. D.M. Nissley, T.G. Meyer, K.P. Walker, Life prediction and constitutive models for engine hot section anisotropic materials program (NASA-CR189223, 1992)

31. Z. Shi, X. Wang, S. Liu, et al, Prog. Nat. Sci 25, 1 78-83 (2015)

32. B.Z. Wang, D.S. Liu, Z.X. Wen, et al, Mat. Sci. Eng. A-Struct 593, 3 31-37 (2014) 